\title{
INTEGRAÇÃO DIGITAL E ANÁLISE ESPACIAL APLICADAS AO ESTUDO DA SUSCETIBILIDADE A INCÊNDIOS FLORESTAIS EM APIAÚ E RIBEIRO CAMPOS - RORAIMA
}

\author{
Gladis de Fátima Nunes da Silva ${ }^{1}$, Stélio Soares Tavares Júnior ${ }^{2}$, \\ Renato Augusto de Oliveira Evangelista ${ }^{2}$, Moisés C. Mourão de Oliveira Júnior ${ }^{3}$ \\ ${ }^{1}$ Geógrafa, M.Sc., Universidade Estadual de Roraima, UERR, Boa Vista, RR, Brasil - gladisilva@hotmail.com \\ ${ }^{2}$ Geólogo, Dr., Depto. de Geologia, UFRR, Boa Vista, RR, Brasil - stelio@dgl.ufrr.br - raevang@zipmail.com.br \\ ${ }^{3}$ Biólogo, M.Sc., Embrapa Roraima, Boa Vista, RR, Brasil - mmourao@cpafrr.embrapa.br \\ Recebido para publicação: 01/08/2007 - Aceito para publicação: 21/04/2008
}

\begin{abstract}
Resumo
A prática de queimadas atinge a maioria dos ecossistemas presentes em Roraima. Em áreas florestais, essa prática somada às alterações climáticas decorrentes do evento El Niño, favorece a entrada de fogo acidental em áreas de florestas primárias, originando incêndios florestais. Nesse contexto, o presente trabalho objetivou analisar os fatores ambientais que contribuem para a ocorrência de incêndios e identificar áreas sob risco de incêndios florestais em Apiaú e Ribeiro Campos (RR), utilizando-se técnicas estatísticas segundo a metodologia da árvore de decisão, análise espacial AHP e integração digital IHS. O emprego da árvore de decisão na hierarquização da importância dos fatores ambientais constitui um avanço em relação a procedimentos empíricos adotados na avaliação de áreas sob risco de incêndios. Os produtos integrados via técnica IHS permitiram a interpretação da variação temática dos fatores ambientais correlacionados espacialmente e espectralmente com as feições fisiográficas em uma única imagem. Os mapas de suscetibilidade resultantes da aplicação da técnica AHP demonstram que existem áreas com alta suscetibilidade a incêndios, indicando a necessidade de maior comprometimento do poder público e da sociedade civil nas ações preventivas à prática de queimadas, para que não tornem a acontecer incêndios similares aos de 1998 e 2003.

Palavras-chave: Floresta tropical; incêndios florestais; sensoriamento remoto; análise espacial e Amazônia.
\end{abstract}

\begin{abstract}
Digital integration and spatial analysis applied to the study of the susceptibility to forest fires in Apiau and Ribeiro Campos - Roraima. The practice of forest fires strikes most of the ecosystems in Roraima. In forest areas, this practice, added to climate changes resulted from the El Niño event, promotes the entrance of accidental fire in primary forest areas originating forest fires. In this context, the present paper objected to analyse the enviromental factors that contribute for the occurrency of fires and identify areas under risk of forest fires in Apiaú and Ribeiro Campos using statistic techniques according to the methodology of the decision tree, AHP space analysis and IHS digital integration in Apiaú and Ribeiro Campos (RR). The use of the decision tree in hierarquization of the evaluation of areas under risk of fires. The integrated products by IHS technique allowed the interpretation of the thematic variation of the enviromental factors spacely and spectraly with phisiografhic fections on just one image. The susceptibility maps resulted from the application of the AHP techinique showed that there are areas with high susceptibility to fires, indicating the need of more commitment of the public power and civil society in preventive actions to fire practices so that fires don't occur again similar to the ones in 1998 and 2003.

Keywords: Tropical rain forest; forest fire; remote sensing; spatial analysis and Amazon.
\end{abstract}

\section{INTRODUÇÃO}

Dentre as formas de degradação do ecossistema florestal tropical, as queimadas e incêndios vêm sendo uma ameaça crescente às florestas da Amazônia (BARLOW; PERES, 2003). Estima-se que 16 mil $\mathrm{km}^{2} /$ ano das florestas da Amazônia são afetados por essa prática. Os incêndios são uma das mais 
importantes fontes de danos aos ecossistemas florestais nas regiões em desenvolvimento. A pressão que essas áreas florestais sofrem devido à necessidade de novas áreas destinadas às atividades agropecuárias tem aumentado consideravelmente o número de incêndios e a extensão das áreas queimadas (BATISTA, 2004). O uso do fogo está arraigado na lógica cultural e econômica dos agricultores e fazendeiros da região amazônica (NEPSTAD et al., 1999; BARBOSA et al., 2004). Nepstad et al. (1999) mencionam que essa lógica é reflexo do modelo de desenvolvimento adotado, no qual o acesso às florestas e à terra é facilitado, favorecendo o seu uso extensivo, tendo o fogo como principal ferramenta de manejo. Nos últimos anos, os incêndios em florestas na Amazônia vêm se tornando cada vez mais freqüentes.

No estado de Roraima (extremo norte amazônico), associadas ao processo de ocupação antrópica nas áreas florestais, destacam-se as queimadas agrícolas, como parte integrante da agricultura itinerante (de corte e queima) e na limpeza de pastagens. Ocasionalmente, as queimadas agrícolas escapam de controle, sendo consideradas incêndios florestais. $O$ avanço do fogo é favorecido também por características ecológicas e microclimáticas das áreas adjacentes, influenciadas, por sua vez, por fenômenos naturais como o El Niño, tendo como conseqüência os incêndios de Roraima em 1998 e 2003 (BARBOSA; FEARNSIDE, 2000; BARBOSA et al., 2004). Em 1998, cerca de 12 mil km² de florestas primárias foram incendiadas, e em 2003, estimou-se que entre os meses de fevereiro e março cerca de 85 $\mathrm{km}^{2}$ de florestas primárias foram diariamente afetados pelo fogo (BARBOSA et al., 2004). A busca pela compreensão dos processos condicionantes da incidência e dinâmica dos incêndios em florestas tropicais torna-se cada vez mais importante, à medida que os efeitos provocados passam a ter repercussões globais negativas, particularmente sobre a atmosfera e o estoque de biodiversidade (COCHRANE, 2003). A diversidade de fatores que afetam o início e a expansão de um incêndio florestal impõe o uso de uma análise integrada, preconizando a utilização de ferramentas de geoprocessamento e sensoriamento remoto. De acordo com Chuvieco; Congalton (1989), o uso de um SIG torna possível atualizar e recuperar informações espaciais, bem como produzir modelos cartográficos por combinação, de diversas maneiras, de planos de informações incluídas no banco de dados. Assim, o SIG pode ser considerado hoje uma técnica indispensável no mapeamento de risco de incêndios, ou seja, a sua utilização viabiliza a aplicação prática do mapeamento de risco. Nesse contexto, o presente trabalho objetivou a identificação dos fatores ambientais que contribuem significativamente para a ocorrência de incêndios em áreas sob risco de incêndios florestais, utilizando-se técnicas estatísticas segundo a metodologia da árvore de decisão, da análise espacial AHP e da integração digital IHS.

Segundo Berry; Linoff (1997), uma árvore de decisão é uma expansão multivariada, consistindo de uma matriz de critérios associados a atributos, onde são aplicados algoritmos de busca desses critérios que evidenciem os atributos definidos, atuando, assim, na redução de um problema complexo em subproblemas mais simples. O Processo Analítico Hierárquico (AHP) funciona como uma ferramenta de suporte à decisão, que consiste na escolha entre alternativas mais ou menos importantes na ocorrência de qualquer processo e é baseada na interseção de mapas temáticos de mesma escala, que constituem os critérios. Essa técnica de escolha é baseada na lógica da comparação pareada, em que os diferentes fatores que influenciam a tomada de decisão são comparados e um critério de importância relativa é atribuído ao relacionamento entre esses fatores, conforme uma escala pré-definida (SAATY, 1986). A partir do estabelecimento de critérios de comparação para cada combinação de fatores, é possível determinar um conjunto de pesos que podem ser utilizados para a geração de diferentes mapas. De acordo com Harris et al. (1990), a integração de dados via transformação IHS (Intensity, Hue, Saturation) permite fundir dados provenientes de fontes diferentes, com o intuito de gerar um produto de boa qualidade visual para as análises quantitativas e qualitativas e para procedimentos de interpretação visual em geral.

\section{CARACTERIZAÇÃO DAS ÁREAS DE ESTUDO}

As áreas abrangem as regiões do Apiaú e de Ribeiro Campos, no município de Mucajaí, centro de Roraima. A região do Apiaú está delimitada pelas coordenadas geográficas $2^{\circ} 30^{\prime} \mathrm{N}$ a $2^{\circ} 34^{\prime} \mathrm{N}$ e $61^{\circ} 16^{\prime} \mathrm{W}$ a $61^{\circ} 22^{\prime} 30^{\prime} \mathrm{W}$, enquanto que a de Ribeiro Campos delimita-se entre $2^{\circ} 20^{\prime} 30^{\prime} \mathrm{N}$ a $2^{\circ} 25^{\prime} 30^{\prime \prime} \mathrm{N}$ e $61^{\circ} 22^{\prime} \mathrm{W}$ a $61^{\circ} 27^{\prime} \mathrm{W}$ (Figura 1). Dentro do contexto geológico, as áreas estão inseridas no domínio estrutural Guiana Central e Parima (CPRM, 1998). Litologicamente, predominam termos magmáticos compostos por sieno a monzogranitos, quartzo monzonito e quartzo sienito da Suíte intrusiva Mucajaí. 
A cobertura vegetal da área é diversificada, sendo composta por Floresta Ombrófila Densa Submontana com dossel uniforme, Floresta Estacional Semidecidual Submontana com dossel uniforme e Vegetação Secundária com palmeiras. O clima da região, segundo a classificação de Köppen, é do tipo Am, predominantemente tropical chuvoso, com período seco definido, principalmente entre os meses de dezembro e março, com temperaturas médias variando entre $25{ }^{\circ} \mathrm{C}$ e $35{ }^{\circ} \mathrm{C}$ (EMBRAPA, 1982; BARBOSA; FEARNSIDE, 2000).

As regiões estudadas exibem forte contato entre quatro grandes grupos de solo: Argissolo Amarelo Distrófico com textura arenosa, Argissolo Amarelo Distrófico com textura argilosa, Neossolo Litólico Distrófico de textura indiscriminada, muito cascalhenta sob afloramentos rochosos, e Argissolo Vermelho Amarelo Distrófico com textura média, pouco cascalhenta/argilosa (RADAMBRASIL, 1975).

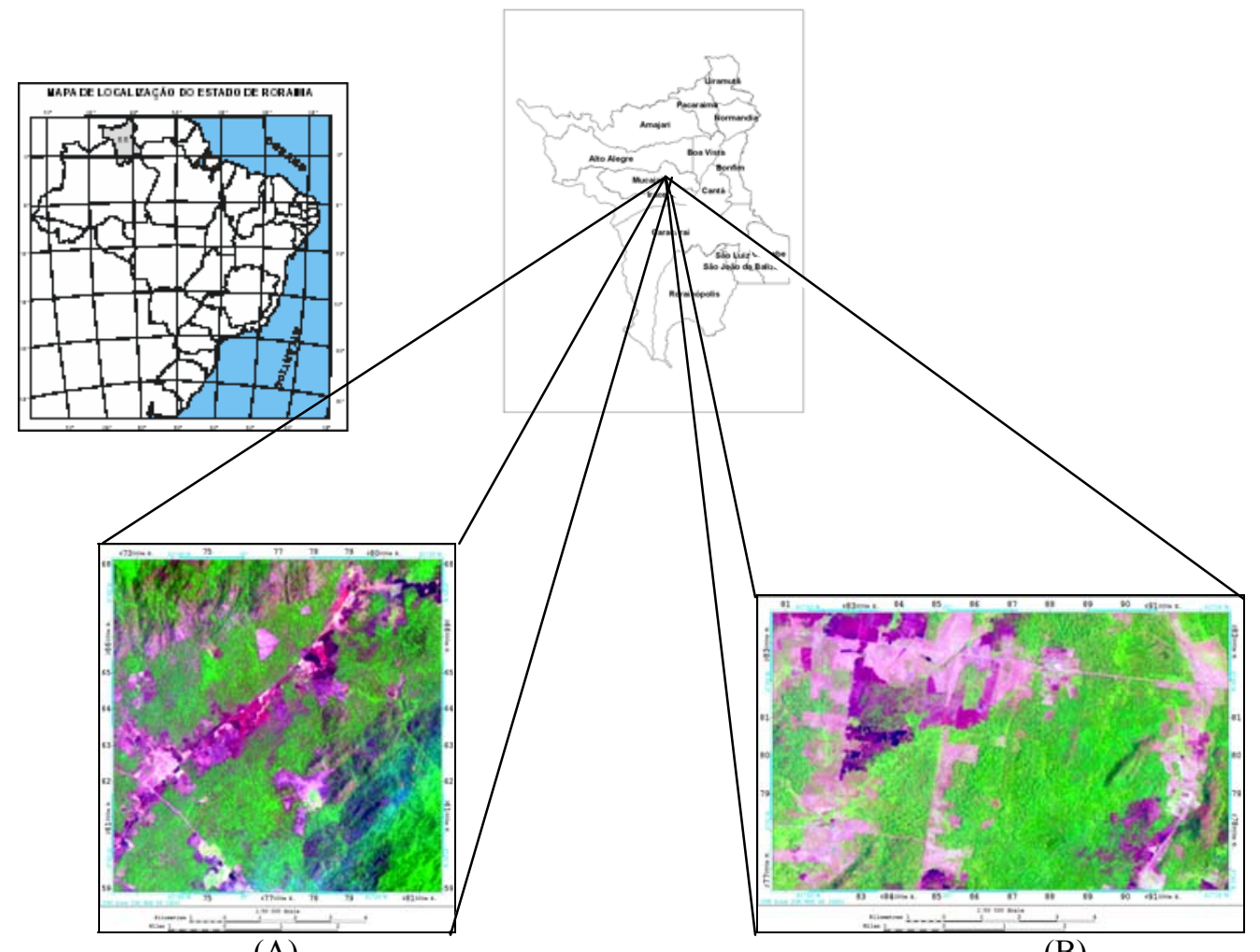

(A)

(B)

Figura 1. Localização das áreas de estudo: Ribeiro Campos (A) e Apiaú (B), Mucajaí (RR) nas imagens Landsat-7/ETM órbita/ponto 232/58 de 17/03/2003 na composição 5 (R) 4 (G) 3 (B).

Figure 1. Location of the studying areas: Ribeiro Campos (A) and Apiaú (B), Mucajaí (RR), on Landsat-7/ETM ${ }^{+}$pictures orbit/dot 232/58 in 17/03/2003 on composition 5 (R) 4 (G) 3 (B).

\section{CONFIGURAÇÃO DOS DADOS E ASPECTOS METODOLÓGICOS}

Neste trabalho, foram utilizados importantes fatores ambientais (naturais e antrópicos) para o estudo da ocorrência de queimadas: focos diários de calor, número de dias sem chuva, risco dos focos de calor, teores de umidade do material combustível e dados altimétricos. Os dados referentes a focos diários de calor, número de dias sem chuva e risco dos focos foram obtidos para o período de 1999 a 2003, junto ao banco de dados de queimadas do INPE, disponibilizados em http:// www.dpi.inpe.br/proarco/bdqueimadas. Dados sobre teores de umidade do material combustível (material vegetal morto, folhas e gravetos com diâmetros inferiores a $2,5 \mathrm{~cm}$, depositados sobre o solo) foram obtidos através de trabalhos de campo. Os dados altimétricos utilizados foram obtidos pelo Shuttle Radar Topography Mission (SRTM), em 2000, com resolução espacial de 90 m, disponibilizados em: http://www.jpl.nasa.gov/srtm/southamericaradarimagens.htm. 
Utilizou-se ainda o conjunto de dados de sensoriamento remoto correspondente às imagens, Landsat-7/ ETM+, órbita/ponto 232/58, de 17/03/2003, e Landsat-5/TM órbita/ponto 232/58, de 18/01/1998, cujas principais características estão dispostas na tabela 1.

Tabela 1. Características das imagens orbitais utilizadas.

Table 1. Characteristics of the used orbital images.

\begin{tabular}{lcccc}
\hline Satélite/Sensor & Órbita/Ponto & Bandas espectrais & Resolução espacial (m) & Data \\
\hline Landsat- 5/TM & $232 / 58$ & $3,4,5$ & $30 \times 30$ & $18 / 01 / 1998$ \\
Landsat -7/ETM & $232 / 58$ & $1,2,3,4,5,6,7$ & $30 \times 30$ & $17 / 03 / 2003$ \\
\hline
\end{tabular}

O desenvolvimento do trabalho apresentou as seguintes etapas: determinação do grau de importância de cada fator ambiental na ocorrência de queimadas e incêndios; trabalho de campo para levantamento de dados sobre teores de umidade do material combustível; elaboração de mapas temáticos para compreensão da dinâmica dos fatores ambientais e sua inter-relação com a propagação do fogo; identificação de áreas que apresentavam condições favoráveis ao risco de fogo, utilizando-se das técnicas árvore de decisão, Processo Analítico Hierárquico (AHP) e integração de dados via técnica IHS, a fim de analisar, em um único produto, as variações espaciais das feições temáticas com as respostas espectrais das imagens Landsat. O fluxograma da figura 2 mostra a seqüência metodológica com as principais etapas adotadas.

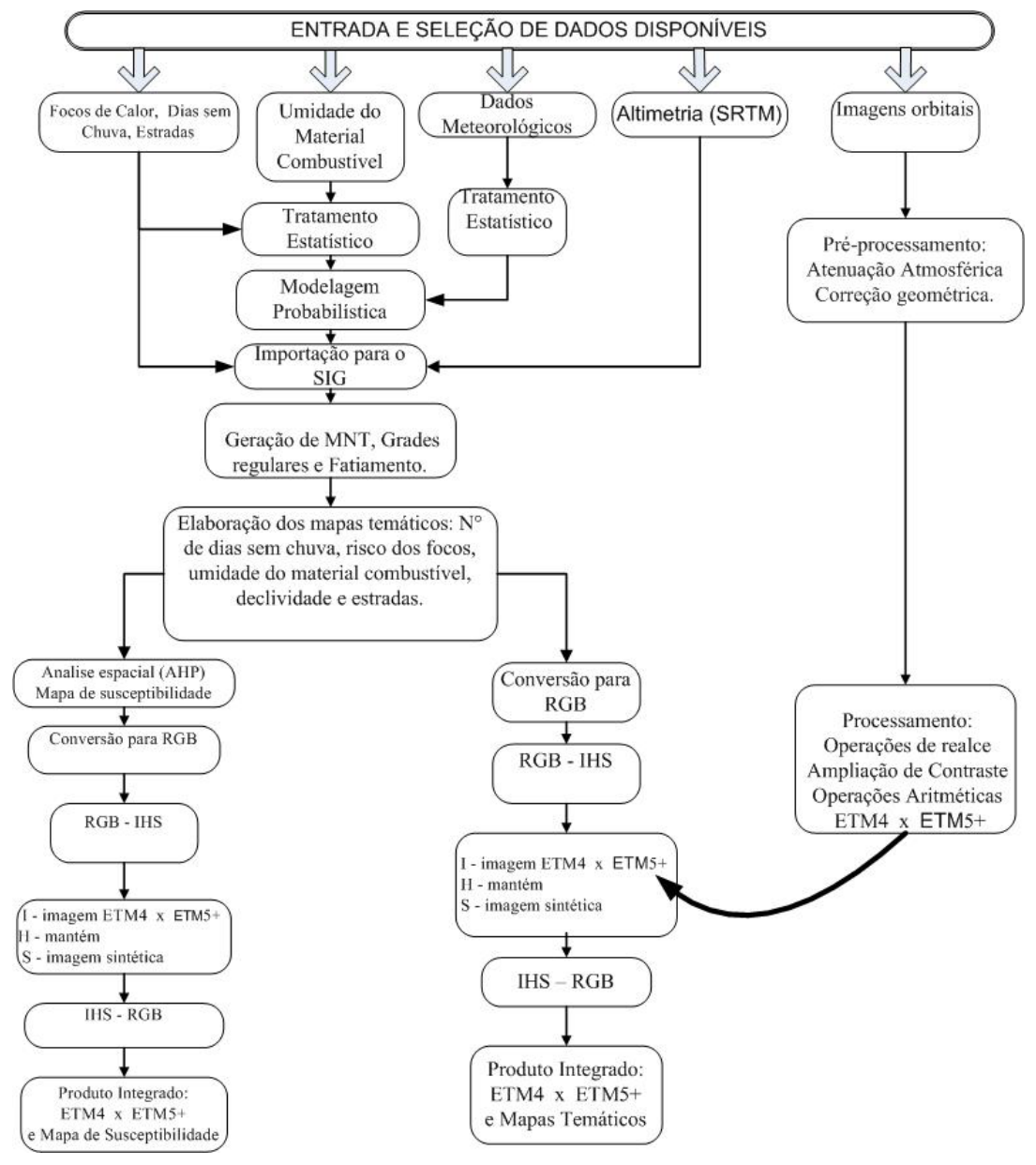

Figura 2. Fluxograma da metodologia adotada.

Figure 2. Flowchart of the adopted methodology. 
O levantamento de dados sobre teores de umidade do material combustível em campo foi realizado entre novembro de 2002 e abril de 2003, com intervalo entre as coletas de quinze dias, realizadas sempre no horário de pico das queimadas $(11 \mathrm{~h} \mathrm{e} 15 \mathrm{~h})$. Levando-se em consideração o horário das coletas e a representatividade dos ecossistemas, as coletas foram realizadas em número de 3 , tomando-se como referencial o primeiro ponto de coleta e os demais distanciando-se dele cerca de $5 \mathrm{~m}$, perfazendo um total de 144 amostras, sendo 76 coletadas em Apiaú e 68 em Ribeiro Campos.

Para identificar, a partir de critérios estatísticos, o grau de importância de cada fator ambiental (natural e antrópico) na ocorrência de queimadas e incêndios, inicialmente utilizou-se a técnica estatística denominada de árvore de decisão. $\mathrm{Na}$ árvore de decisão, empregaram-se como indicadores: número e focos de calor (rank da média da série histórica 1999 a 2003), precipitação (rank da média da série histórica 1999 a 2003), vias de acesso e relevo. Como critério de risco de fogo, foi utilizado o limiar de $10 \%$ da umidade do material combustível, com base em trabalhos desenvolvidos na região (BARBOSA et al., 2004). Os dados foram analisados por meio da técnica de árvore de decisão, a qual consiste na definição de limiares, combinações lineares ou freqüências de ocorrência, de uma série de variáveisresposta, a partir da freqüência de ocorrência de um dado nível de realização de uma variável classificatória definida, no caso, intensidade de ocorrência de fogo. As análises foram conduzidas com auxílio do pacote estatístico Statistica, tendo como base o algoritmo C\&RT (STATSOFT, 1999), o qual é definido como um buscador de dicotomias, as quais são validadas por meio de um teste de qui-quadrado de contingência (BREIMAN et al., 1984).

Para compreender a dinâmica dos fatores ambientais e sua inter-relação com a propagação do fogo, foram elaborados mapas temáticos da declividade, da umidade do material combustível, do risco dos focos de calor e do número de dias sem chuva. Inicialmente, geraram-se modelos numéricos do terreno (MNT): geração de grade regular, utilizando-se o interpolador média ponderada por cota e por quadrante, seguida do fatiamento em intervalos de classes, da geração de imagens em nível de cinza e da conversão para o espaço RGB, através da aplicação de uma tabela de pseudocores.

Para compreender a dinâmica do uso do fogo em áreas com intensa rede viária, foram construídos mapas de distâncias que consistem na criação de buffers (áreas de influência) com larguras específicas (distâncias) em torno da rede viária. O critério adotado para o estabelecimento das classes e níveis de risco dos mapas temáticos referentes às distâncias a estradas foi baseado em análises das atividades antrópicas desenvolvidas, feitas através de observação de campo e interpretação de imagens Landsat 7/ETM mais recentes. Nas regiões em questão, essas atividades ocorrem com maior intensidade próximo das vias de acesso.

Os intervalos de classes e níveis de risco dos mapas temáticos referentes a número de dias sem chuva e risco dos focos de calor foram definidos na forma de três intervalos iguais, considerando-se os limites máximos e mínimos encontrados. Os intervalos de classes referentes à umidade do material combustível foram estabelecidos com base nos dados obtidos por trabalhos de monitoramento do material combustível realizado na região (BARBOSA et al., 2004), porém foram acrescidas algumas modificações em razão de particularidades de valores obtidos, tais como ausência de valores presentes nas classes definidas por Barbosa et al. (2004). As classes e níveis de risco adotados para os fatores ambientais analisados podem ser observados na tabela 2.

A identificação de áreas que apresentavam condições favoráveis ao risco de fogo foi realizada através do Processo Analítico Hierárquico (AHP). Nessa etapa do trabalho, os mapas temáticos gerados referentes aos fatores ambientais foram comparados pareadamente quanto à sua importância relativa na deflagração do processo das queimadas, e, segundo essa importância, foram calculados os pesos numéricos de cada um deles no processo sob análise. Cabe ressaltar que o grau de importância entre os fatores ambientais considerados foi resultante da aplicação da árvore de decisão, na qual o algoritmo utilizado indicou a importância das variáveis classificatórias, sob a seguinte ordem (consistindo esta de uma escala de importância variando de $0-100$, em que 100 assinala a maior importância): precipitação (100), relevo (85), sazonalidade dos focos de calor (83) e vias de acesso (52). A comparação das importâncias entre os fatores ambientais resultou em MNT final, que em seguida foi fatiado em classes susceptíveis à ocorrência de fogo.

O processamento das imagens digitais Landsat-7 e Landsat-5 consistiu nas operações de préprocessamento (atenuação dos efeitos atmosféricos e correção geométrica), além das operações de realce e integração de dados digitais. Na atenuação dos efeitos atmosféricos, optou-se pela utilização da técnica de subtração do pixel escuro, na qual alvos com tonalidades escuras são utilizados para determinar o valor de correção de cada banda (CRANE, 1971). A correção geométrica foi feita através da aplicação de 
transformação polinomial de $3^{\circ}$ grau, com a coleta de 15 pontos de controle para cada área. A reamostragem dos pixels da imagem foi realizada pelo método de convolução cúbica. Com a finalidade de melhorar a qualidade visual e, por conseguinte, a discriminação dos alvos de interesse, realizaram-se operações de ampliação de contraste para cada banda ETM (3, 4 e 5), de modo a expandir a amplitude original dos níveis de cinza para todo o intervalo $(0,255)$. Nessa etapa, foi aplicada a função raiz, também conhecida como transformação logarítmica. Essa ampliação de contraste é bastante eficaz em imagens que apresentam assimetria na distribuição dos níveis de cinza, como é o caso das áreas de estudo (parte da vegetação densa, parte desmatada e áreas de antropizadas com lavouras e pastagens).

Tabela 2. Classes e níveis de risco dos fatores ambientais.

Table 2. Classes and levels of risk of environmental factors.

\begin{tabular}{|c|c|}
\hline Classes & $\begin{array}{l}\text { Níveis de risco } \\
\end{array}$ \\
\hline & Umidade do material combustível Apiaú e Ribeiro Campos (\%) \\
\hline $5-8$ & Baixo \\
\hline $8-12$ & Médio \\
\hline $12-25$ & Alto \\
\hline \multirow[t]{2}{*}{$>25$} & Muito alto \\
\hline & Número de dias sem chuva Apiaú e Ribeiro Campos \\
\hline $1-5$ & Baixo \\
\hline $5-10$ & Médio \\
\hline \multirow{2}{*}{$10-27$} & Alto \\
\hline & Risco dos focos de calor Apiaú \\
\hline $0-0,035$ & Baixo \\
\hline $0,035-0,70$ & Médio \\
\hline \multirow[t]{2}{*}{$0,70-1,05$} & Alto \\
\hline & Risco dos focos de calor Ribeiro Campos \\
\hline $0,00142-0,0351$ & Baixo \\
\hline $0,0351-0,70$ & Médio \\
\hline \multirow[t]{2}{*}{$0,70-1,05$} & Alto \\
\hline & Distância a estradas Apiaú e Ribeiro Campos (m) \\
\hline $0-1000$ & Alto \\
\hline 1000-2000 & Médio \\
\hline \multirow[t]{2}{*}{$2000-10000$} & Baixo \\
\hline & Declividade Apiaú e Ribeiro Campos $\left({ }^{\circ}\right)$ \\
\hline $0-3$ & Muito baixo \\
\hline $3-9$ & Baixo \\
\hline $9-15$ & Médio \\
\hline $15-21$ & Alto \\
\hline$>30$ & Muito alto \\
\hline
\end{tabular}

A operação aritmética de multiplicação entre as bandas ETM4 e ETM5 da imagem Landsat7/ETM ${ }^{+}$foi utilizada com o objetivo de permitir a compressão de dados e o realce das feições do relevo e, por conseguinte, da vegetação, a qual tende a acompanhar os grandes traços do relevo. A metodologia empregada para a geração dos produtos integrados foi a transformação Intensity-Hue-Saturation (IHS), em razão de sua flexibilidade, por permitir o controle individual sobre os atributos IHS (HARRIS et al., 1990). Na execução dessa técnica, as imagens RGB dos mapas temáticos serviram de entrada para a conversão RGB $\rightarrow$ IHS. Ao retornar ao espaço de cores RGB, através da aplicação da transformação inversa IHS $\rightarrow$ RGB, o canal intensidade (I) foi substituído pela imagem multiplicada (ETM4 x ETM5), o componente matiz $(\mathrm{H})$ foi mantido e o de saturação $(\mathrm{S})$ foi substituído pelo valor digital constante 60 (saturação sintética).

\section{RESULTADOS}

As interpretações sobre o produto integrado demonstrado na figura 3 e os dados de campo no Apiaú indicaram que os maiores teores de umidade do material combustível distribuem-se em regiões de 
maior concentração de florestas, onde provavelmente ocorre uma menor exposição à luz solar, mantendose dessa forma elevados índices de umidade. Áreas que apresentam baixos teores de umidade ocorrem em locais de forte antropização, próximas às vias de acesso. Na figura 4, observa-se que em Ribeiro Campos os maiores teores de umidade do material combustível encontram-se distribuídos após a presença de serras que não apresentam a estrutura vegetal original.

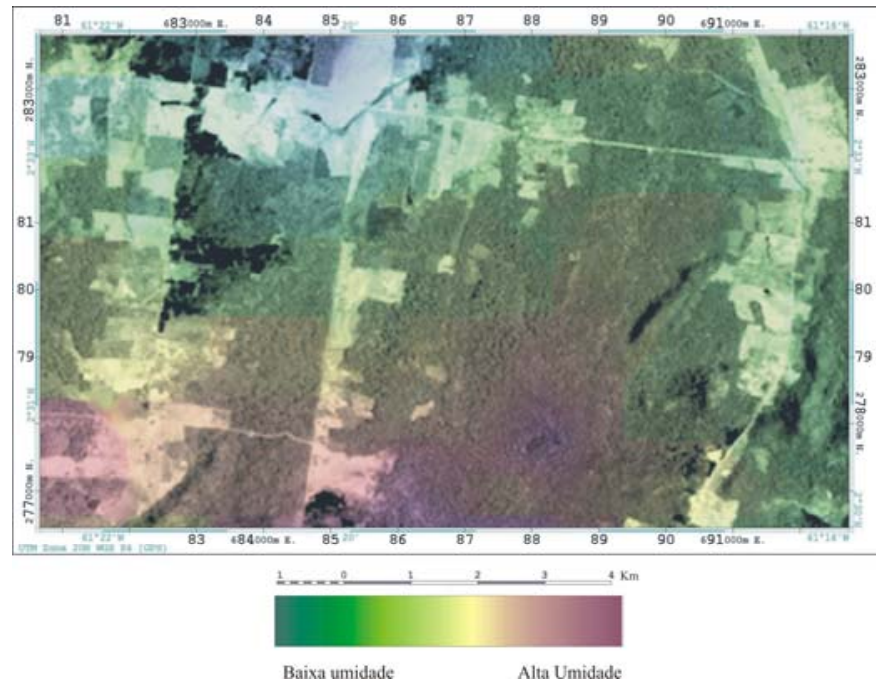

Figura 3. Produto integrado Landsat-7/ETM ${ }^{+}$(ETM4 x ETM5) e distribuição espacial da umidade do material combustível em Apiaú, Mucajaí (RR).

Figure 3. Landsat-7/ETM ${ }^{+}$(ETM4 x ETM5) integrated product and spatial distribution of the fuel material in Apiaú, Mucajaí (RR).

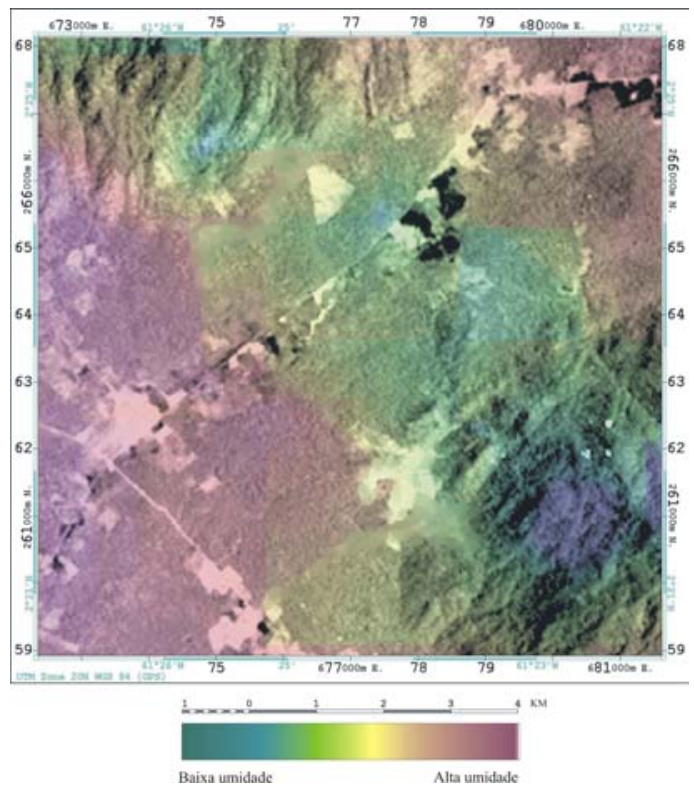

Figura 4. Produto integrado Landsat-7/ETM+ (ETM4 x ETM5) e distribuição espacial da umidade do material combustível em Ribeiro Campos, Mucajaí (RR).

Figure 4. Landsat-7/ETM+ (ETM4 x ETM5) integrated product and spatial distribution of the fuel material in Ribeiro Campos, Mucajaí (RR). 
Na figura 5, é ilustrada a distribuição do número de dias sem chuva para a localidade do Apiaú. Observa-se que há poucas áreas apresentando elevado número de dias sem chuva, enquanto que na figura 6, em Ribeiro Campos, há a existência de áreas isoladas que apresentam muitos dias sem chuva. É importante salientar que a diminuição da oferta pluviométrica associada a outras variáveis meteorológicas contribui de forma decisiva para a potencialização dos incêndios florestais.

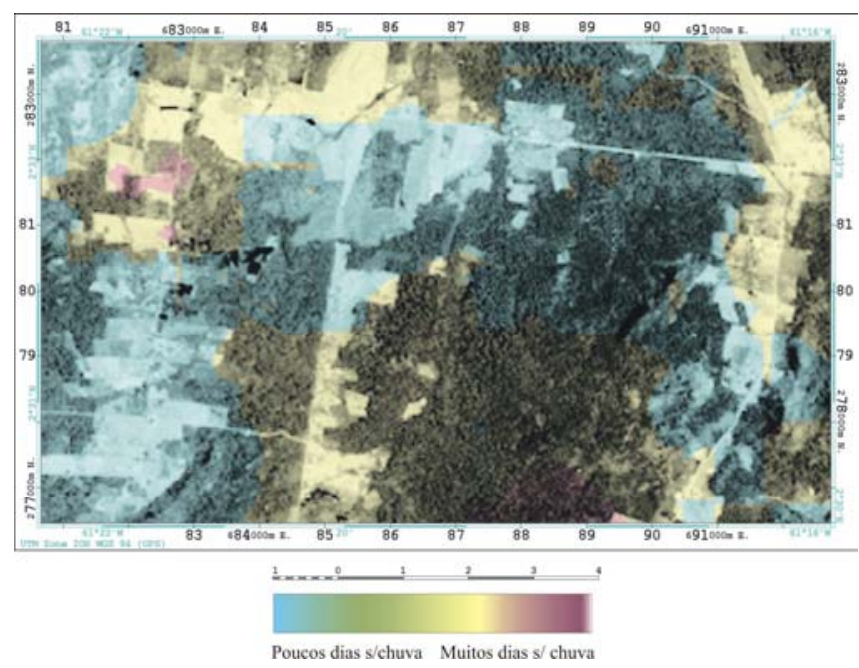

Figura 5. Produto integrado Landsat-7/ETM+ (ETM4 x ETM5) e distribuição espacial do número de dias sem chuva em Apiaú, Mucajaí (RR).

Figure 5. Landsat-7/ETM+ (ETM4 x ETM5) integrated product and spatial distribution of the number of the days without rain in Apiaú, Mucajaí (RR).

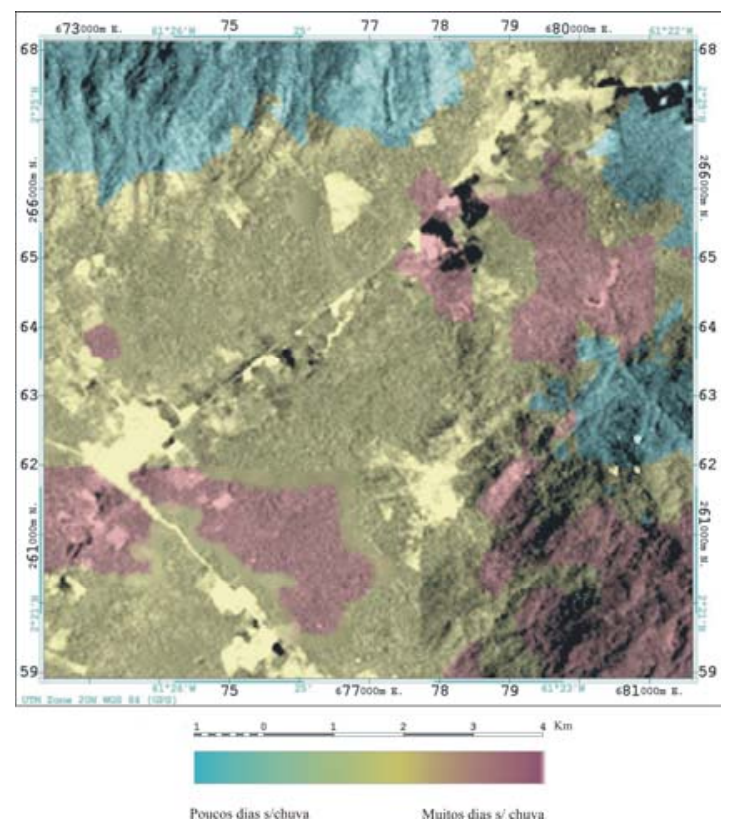

Figura 6. Produto integrado Landsat-7/ETM+ (ETM4 x ETM5) e distribuição espacial do número de dias sem chuva em Ribeiro Campos, Mucajaí (RR).

Figure 6. Landsat-7/ETM+ (ETM4 x ETM5) integrated product and spatial distribution of the number of the days without rain in Ribeiro Campos, Mucajaí (RR). 
Segundo Soares (1985), existe uma forte correlação entre a ocorrência de grandes incêndios e prolongados períodos de secas. Longos períodos de estiagem afetam o potencial de propagação dos incêndios de diversas maneiras, principalmente pela secagem do material combustível morto, que pode afetar o teor de umidade da vegetação verde, aumentando a probabilidade de ignição e a facilidade de propagação do incêndio.

Nesse contexto, Uhl; Kauffman (1990) afirmam que florestas intactas resistem ao fogo mesmo após 16 dias sem chuva, mas áreas já queimadas são mais vulneráveis: 90\% da área de floresta queimada mais de duas vezes são susceptíveis ao fogo com poucos dias sem chuva, e a pequena parcela que escapa não resiste a uma seca maior. Em áreas de florestas exploradas, grandes clareiras podem queimar após somente 5 a 6 dias sem chuva na estação seca.

A figura 7 ilustra a distribuição do risco dos focos de calor para a localidade de Apiaú. Verificase que em áreas de maior antropização registra-se a maior incidência de focos de calor e maior risco de incêndios.

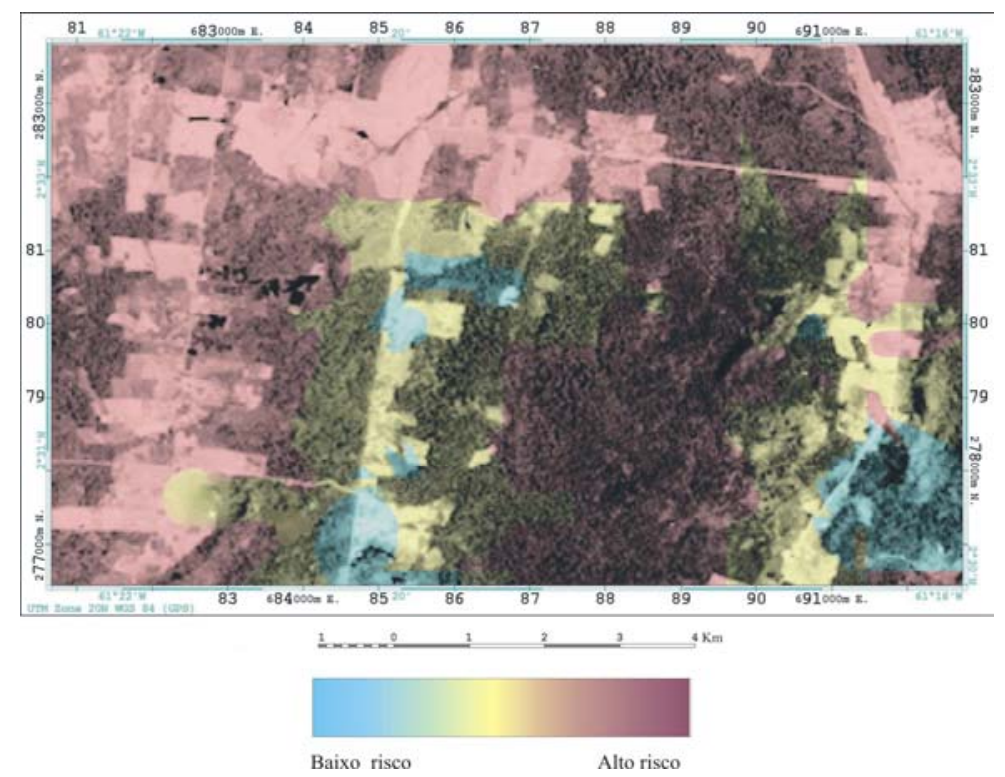

Figura 7. Produto integrado Landsat-7/ETM+ (ETM4 x ETM5) e distribuição espacial do risco dos focos de calor em Apiaú, Mucajaí (RR).

Figure 7. Landsat-7/ETM+ (ETM4 x ETM5) integrated product and spatial distribution of the risk of heat areas in Apiaú, Mucajaí (RR).

A maior incidência de focos de calor em áreas predominantemente antropizadas revela que os incêndios, na maioria das vezes, ocorrem de maneira intencional, motivados pela necessidade de novas áreas para pastagens e lavouras, sendo o fogo utilizado com ferramenta de manejo do solo. Segundo Ferraz; Vetorazzi (1998), quando um foco de calor não é controlado imediatamente, o incêndio é estabelecido e seu combate é dificultado por vários fatores, entre os quais, o tamanho do fragmento, a falta de recursos próprios para o combate, a falta de acessos adequados e a ausência de organização das comunidades afetadas.

$\mathrm{Na}$ figura 8, observa-se que em Ribeiro Campos as áreas que apresentam maior incidência e risco de focos de calor são áreas das encostas limítrofes às áreas antropizadas. Durante a estação seca, essas áreas tornam-se mais vulneráveis aos incêndios acidentais. De acordo com Barbosa; Fearnside (2000), os principais focos de calor registrados na área florestal de Roraima em 1998 partiram também da região do Apiaú e de Ribeiro Campos.

Quanto à declividade em Apiaú (Figura 9), observa-se que há uma variação desde terrenos planos a ligeiramente ondulados predominantes até áreas com terrenos ondulados com a presença de serras isoladas. Essas últimas constituem áreas que favorecem a propagação do fogo. As áreas planas 
constituem-se litologicamente por termos mais antigos que sofreram vários processos erosivos e por área de pediplanação. As áreas mais elevadas são sustentadas pelas principais litologias representantes da Suíte Intrusiva Mucajaí. Em Ribeiro Campos (Figura 10), verifica-se uma variação desde terrenos suavemente planos até terrenos muito acidentados, representados por encostas das serras e acentuando-se nos topos das mesmas.

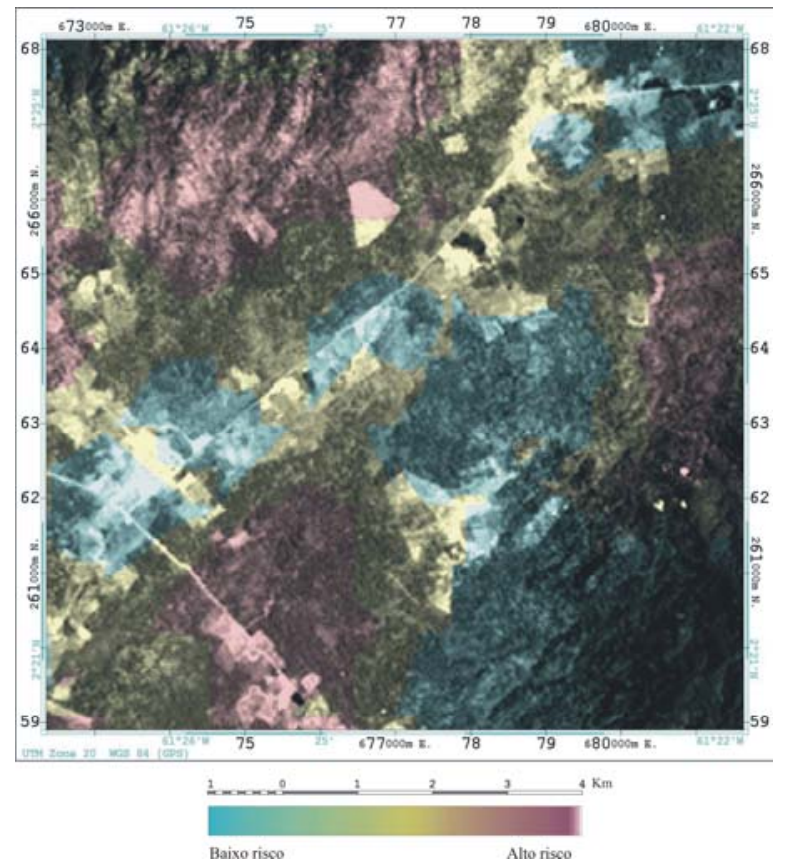

Figura 8. Produto integrado Landsat-7/ETM+ (ETM4 x ETM5) e distribuição espacial do risco dos focos de calor em Ribeiro Campos (RR).

Figure 8. Landsat-7/ETM+ (ETM4 x ETM5) integrated product and spatial distribution of the risk of heat areas in Ribeiro Campos, Mucajaí (RR).

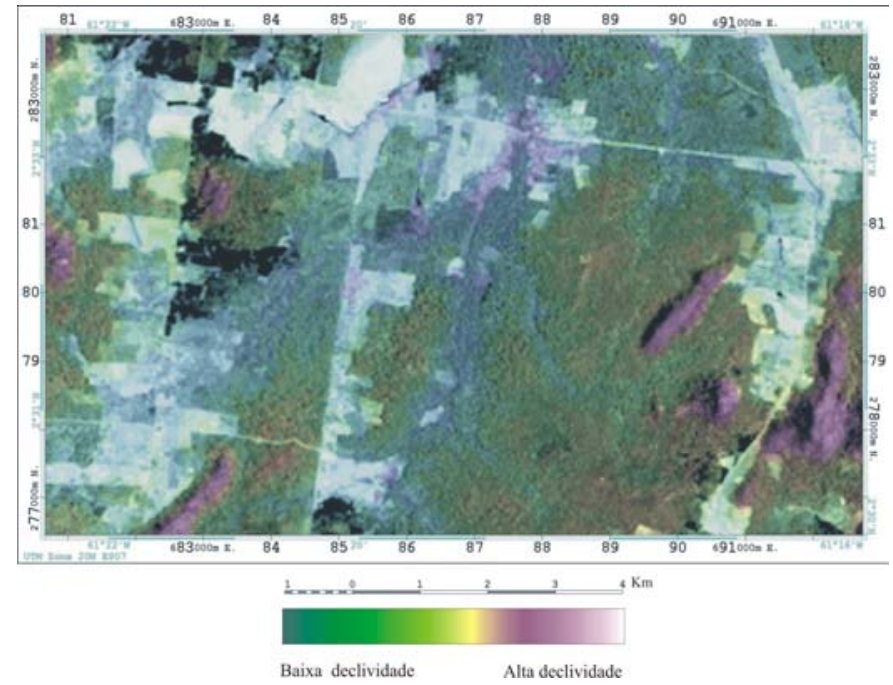

Figura 9. Produto integrado SRTM e distribuição espacial da declividade em Apiaú, Mucajaí (RR).

Figure 9. Landsat-7/ETM+ (ETM4 x ETM5) integrated product and spatial distribution of the declivity in Apiaú, Mucajaí (RR). 


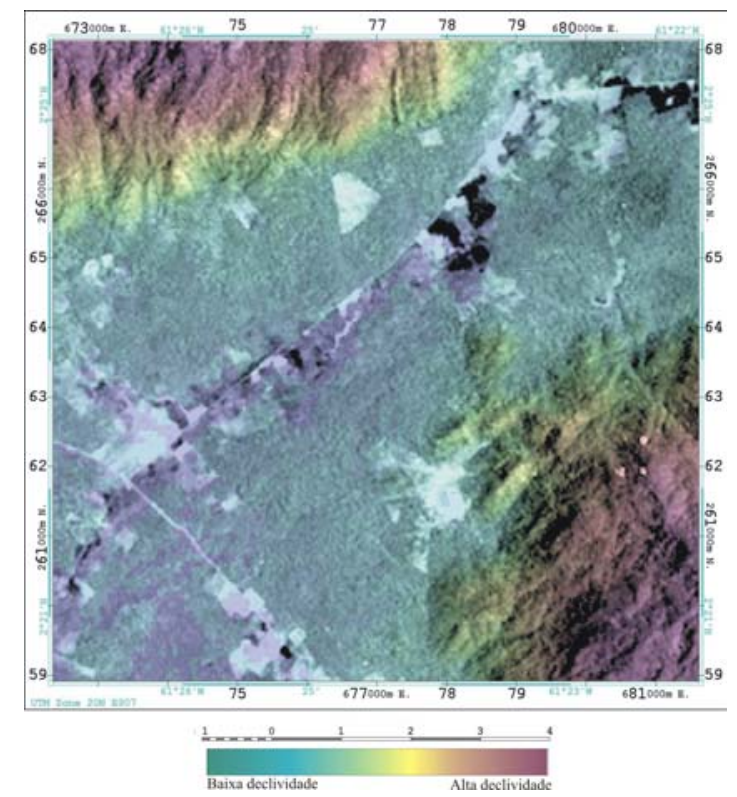

Figura 10. Produto integrado SRTM e distribuição espacial da declividade da região de Ribeiro Campos, Mucajaí (RR).

Figure10. Landsat-7/ETM+ (ETM4 x ETM5) integrated product and spatial distribution of the declivity in Ribeiro Campos, Mucajaí (RR).

As figuras 11 e 12 demonstram as classes de distâncias das estradas relacionadas com o risco de incêndios das localidades de Apiaú e Ribeiro Campos. Observa-se, tanto em Apiaú como em Ribeiro Campos, que existem extensas áreas que apresentam elevada influência no risco dos incêndios. Com o estabelecimento de projetos de colonização ao longo de estradas (tronco e vicinais), aumenta a ocorrência e o risco de incêndios, uma vez que as estradas permitem um maior acesso às áreas florestais, possibilitando dessa forma a intensificação do uso do solo com atividades agrícolas e pastoris, nas quais o fogo é largamente utilizado como prática de manejo.

De acordo com IBGE (2002), a abertura de estradas na Amazônia tem tido conseqüências desastrosas ao longo de sua história recente, afetando a preservação da floresta não só pela expansão pioneira das madeireiras, já que a estas se sucede, usualmente, um processo de desorganização fundiária, de apropriação irregular de estabelecimentos rurais e principalmente de expansão da produção agropecuária.

$\mathrm{Na}$ figura 13, visualiza-se a suscetibilidade a incêndios florestais para a localidade do Apiaú. Analisando-se o mapa integrado de suscetibilidade resultante da aplicação da técnica AHP, nota-se que áreas com alta suscetibilidade ocorrem sob a forma de manchas isoladas, distribuídas em áreas ao $\mathrm{S} \mathrm{e}$ NW, em locais antropizados ou não.

Áreas com suscetibilidade intermediária apresentam-se distribuídas sob a forma de manchas isoladas ao N, NW, NE e S. Ocorrem em áreas florestadas e antropizadas, sob relevo plano. Ressalte-se que essas áreas encontram-se próximas às vias de acesso e são fortemente antropizadas. Observa-se ainda no mapa que há um corredor no sentido NE-SW, com áreas apresentando baixa suscetibilidade. Elas ocorrem sob áreas florestadas e antropizadas. Lombardi (2001), utilizando diferentes métodos de inferência espacial para identificar áreas que apresentavam condições favoráveis à ocorrência de incêndios florestais em uma área de Paragominas, no Pará, afirma que a AHP é uma técnica apropriada para se identificarem áreas sob risco de incêndios, pois permite a espacialização das áreas vulneráveis à ocorrência dos incêndios florestais conforme o peso atribuído para cada variável estudada, identificando as áreas de maior risco, segundo a importância relativa que essas variáveis apresentam. 


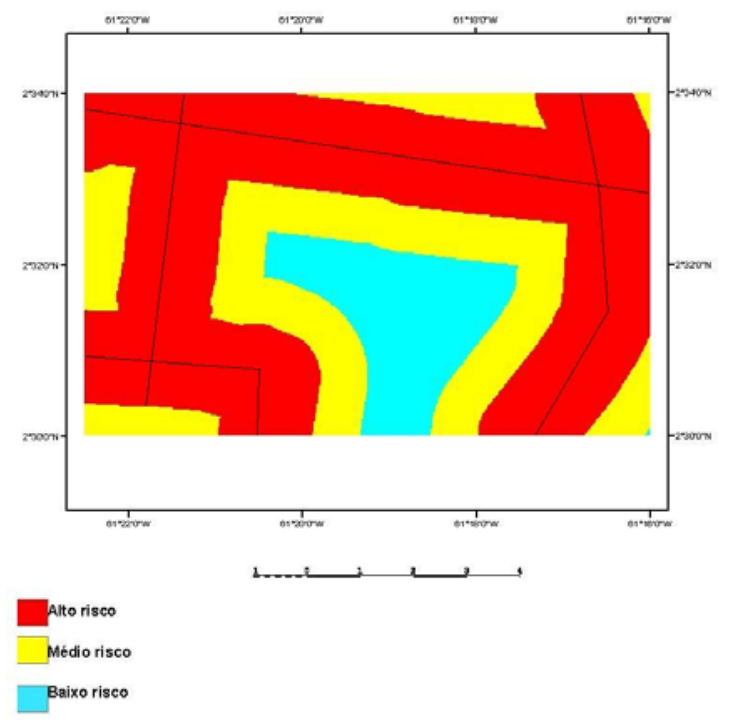

Figura 11. Mapa temático das classes de distâncias das estradas relacionadas com o risco de incêndios florestais em Apiaú, Mucajaí (RR).

Figure 11. Thematic map of distance roads classes related to the risk of forest fires in Apiaú, Mucajaí (RR).

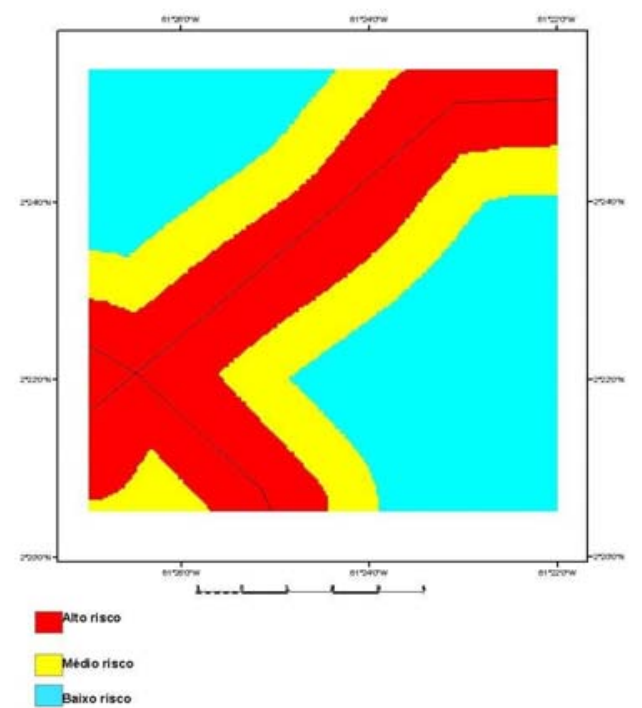

Figura 12. Mapa temático das classes de distâncias das estradas relacionadas com o risco de incêndios florestais em Ribeiro Campos, Mucajaí (RR).

Figure 12. Thematic map of distance roads classes related to the risk of forest fires in Ribeiro Campos, Mucajaí (RR).

A figura 14 demonstra a suscetibilidade a incêndios florestais para a localidade de Ribeiro Campos. Observam-se extensas áreas com alta suscetibilidade para a ocorrência de incêndios. Elas aparecem sob a forma de grandes manchas isoladas, ocorrendo em todos os quadrantes da área, situadas sobre as encostas e os topos das serras. Observa-se, ainda, que há poucas áreas com baixa suscetibilidade à ocorrência de incêndios em Ribeiro Campos. A distribuição é isolada sob a forma de mancha a NE, próxima às vias de acesso e caracteriza-se por ser antropizada. 


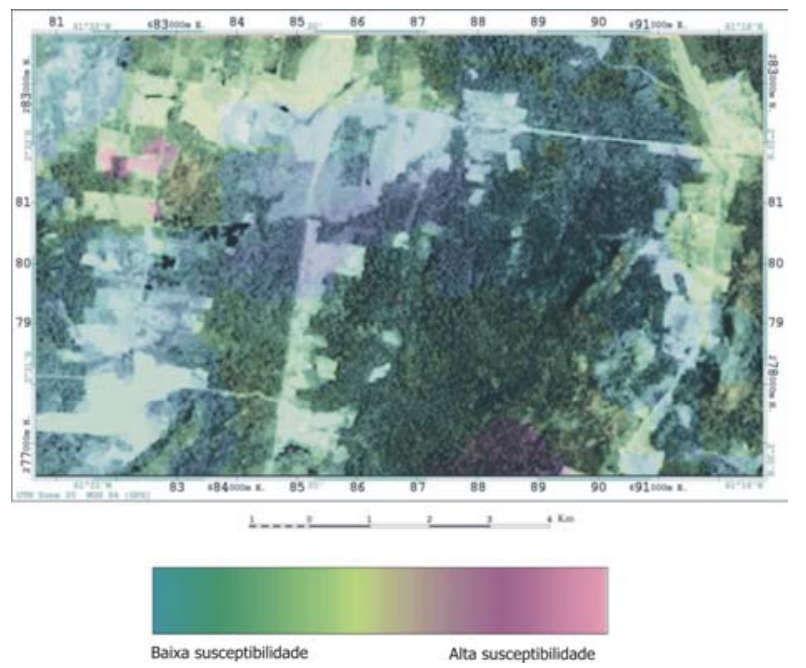

Figura 13. Produto integrado Landsat-7 (ETM4 x ETM5) e mapa de suscetibilidade (AHP) a incêndios florestais na região do Apiaú, Mucajaí (RR). Destaca-se que as áreas com alta suscetibilidade a incêndios florestais ocorrem de forma isolada tanto em áreas de floresta como em áreas antropizadas.

Figure 13. Landsat-7/ETM+ (ETM4 x ETM5) integrated product and susceptibility map (AHP) in the area of Apiaú, Mucajaí (RR). The areas with high susceptibility to forest fires occur in an isolated form such in forest areas as in antropized areas. It's observed that there are several areas presenting low susceptibility.

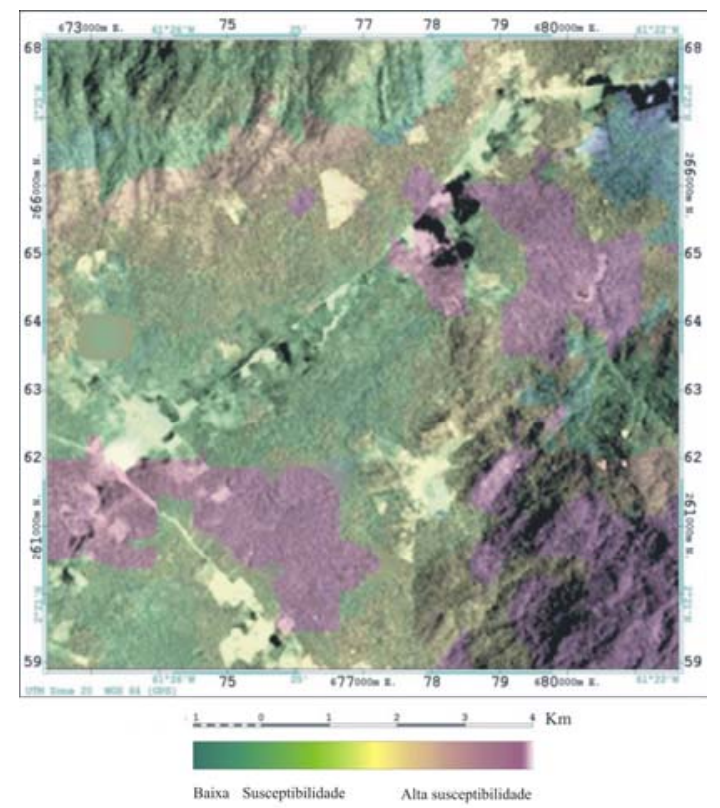

Figura 14. Produto integrado Landsat-7 (ETM4 x ETM5). Mapa de suscetibilidade (AHP) a incêndios florestais em Ribeiro Campos, Mucajaí (RR). Nota-se a presença de extensas áreas com alta suscetibilidade para a ocorrência de incêndios florestais situadas sobre as encostas e os topos das serras.

Figure 14. Landsat-7/ETM+ (ETM4 x ETM5) integrated product and susceptibility map (AHP) in the area of Ribeiro Campos, Mucajaí (RR). The presence of large areas can be observed with to high susceptibility to the occurrence of forest fires located on the shores and the top of the mountains. 
Os mapas de suscetibilidade gerados são instrumentos que fornecem subsídios para a tomada de decisões, uma vez que identificam a distribuição espacial das áreas sob risco de incêndios, tornando possível a definição de prioridades em ações de prevenção, combate e controle dos incêndios por parte do poder público e da sociedade civil organizada.

\section{CONCLUSÕES}

A integração no espaço IHS forneceu produtos nos quais as informações texturais e espectrais dos alvos foram otimizadas em um único produto, que permitiu a interpretação da variação temática dos fatores ambientais declividade, umidade do material combustível, número de dias sem chuva, distância das estradas e risco dos focos de calor, correlacionados espacialmente e espectralmente tanto com as feições fisiográficas das áreas (solo, vegetação, relevo) quanto com as feições antropizadas, em uma única imagem.

Essa visão integrada torna-se importante pela dificuldade em se identificar áreas de risco pela análise isolada de cada fator, principalmente em áreas que apresentam diversidade de fatores de risco. Através da interpretação dos produtos obtidos e verificações de campo, pode-se inferir que, em áreas antropizadas, o risco de fogo eleva-se, em função da diminuição da umidade do material combustível, indicando a necessidade de maior controle de queimadas na área.

Os mapas de suscetibilidade a incêndios florestais gerados a partir de análise espacial, via técnica AHP, permitiram a visualização de áreas críticas quanto aos incêndios florestais em Apiaú e Ribeiro Campos, fornecendo subsídios para a tomada de decisão em relação às queimadas e incêndios, uma vez que possibilita uma análise com todos os condicionantes que contribuem para a ocorrência dos incêndios florestais.

O emprego da árvore de decisão na hierarquização da importância dos fatores ambientais constitui um avanço em relação a procedimentos empíricos adotados na avaliação de áreas sob risco de incêndios. Os mapas de suscetibilidade resultantes da aplicação da técnica AHP demonstraram que existem áreas que apresentam alta suscetibilidade a incêndios em Apiaú e Ribeiro Campos, indicando a necessidade de maior comprometimento do poder público e da sociedade civil nas ações preventivas à prática de queimadas, para que não tornem a acontecer incêndios similares aos de 1998 e 2003.

\section{REFERÊNCIAS}

BARBOSA, R. I.; FEARNSIDE, P. M. Erosão do solo na Amazônia: Estudo de caso na região do Apiaú, Roraima, Brasil. Acta Amazônica, Manaus, v. 30, n. 4, 2000.

BARBOSA, R. I.; XAUD, M. R.; SILVA, G. F. N.; CATTÂNEO, A. C. Cinzas na Amazônia: incêndios florestais reencontram Roraima. Ciência Hoje, Rio de Janeiro, v. 35, n. 207, 2004.

BARLOW, J.; PERES, C. A. Fogo rasteiro: nova ameaça na Amazônia. Ciência Hoje, Rio de janeiro, v. 34, n. 199, 2003.

BATISTA, A. B. Detecção de incêndios florestais por satélites. Floresta, Curitiba, v. 34, n. 2, 2004.

BERRY, M. J. A.; LINOFF, G. Data mining techniques. New York: J. Wiley \& Sons, 1997.

BRASIL. Ministério das Minas e Energia. Projeto RADAMBRASIL, Folha NA.20-Boa Vista e parte das folhas NA.21 Tumucumaque, NB.20 Roraima e NB.21, geologia, geomorfologia, pedologia, vegetação e uso potencial da terra.Rio de Janeiro: Secretaria Geral, 1975. (Levantamento de Recursos Naturais, v.8).

BREIMAN, L.; FRIEDMAN, J. H.; OLSHEN, R. A.; STONE, C. J. Classification and regression trees. Monterey, CA: Wadsworth \& Brooks/Cole Advanced Books \& Software, 1984.

CHUVIECO, E.; CONGALTON, R. G. Application of Remote Sensing and Geographic Information Sistems to Forest Fire Hazard Mapping. Remote Sensing of Environment, New York, v. 29, p. 147-159, 1989.

COCHRANE, M. A. Fire science for rainforests. Nature, London, v. 421, 2003. 
COMPANHIA DE PESQUISA EM RECURSOS MINERAIS (CPRM). Projeto Roraima Central (folhas NA. 20 -X-B e NA-X-D e parte das folhas NA. 20-X-A, NA. 20-X-C, NA. 21-V-A e NA.21-VC).1998. Disponível em: <http://www.cprm.gov.br >. Acesso em: 22/08/2006.

CRANE, R. B. Preprocessing techniques to reduce atmospheric and sensor variability in multispectral scanner data. In: INTERNATIONAL SYMPOSIUM ON REMOTE SENSING OF ENVIRONMENT, 7., 1971. Proceedings... Michigan: Center for Remote Sensing Information and Analysis, 1971.

EMPRESA BRASILEIRA DE PESQUISA EM AGROPECUÁRIA (EMBRAPA). Levantamento de Reconhecimento de Baixa Intensidade dos Solos e Avaliação da Aptidão Agrícola das Terras do Projeto de Colonização Apiaú - Território Federal de Roraima. Rio de Janeiro, 1982. (Boletim de Pesquisa, n. 14)

FERRAZ, S. F. B; VETORAZZI, C. A. Mapeamento de Risco de Incêndios Florestais por meio de sistemas de informações geográficas (SIG). Scientia Forestalis, Piracicaban, n. 53, p. 39-48, jun. 1998.

HARIS, J. R.; MURRAY, R.; HIROSE, T. HIS transform for the integration of radar imagery whith remotely sensed data. Photogrammetric engineering and remote sensing, New York, v. 56, n. 12, 1990.

INSTITUTO BRASILEIRO DE GEOGRAFIA E ESTATÍSTICA (IBGE). Perfil dos municípios brasileiros: meio ambiente. Brasília, DF, 2002.

LOMBARDI, R. J. R. Identificação de áreas vulneráveis à ocorrência de incêndios florestais, provocados por atividades antrópicas, utilizando diferentes métodos de inferência espacial. In: SIMPÓSIO BRASILEIRO DE SENSORIAMENTO REMOTO, 10., 2001. Foz do Iguaçu. Anais... São José dos Campos: INPE, 2001.

NEPSTAD, D. C.; MOREIRA, A. G.; ALENCAR, A. A. A floresta em chamas: origens, impactos e prevenção de fogo na Amazônia. Brasília: Programa Piloto para a Proteção das Florestas Tropicais do Brasil, 1999.

SOARES, R. V. Incêndios florestais: controle e uso do fogo. Curitiba: Fundação de Pesquisas do Paraná, 1985.

SAATY, T. L. Axiomatic foundation of the analiticy hierarchy process. Management Science, Providence, v. 32 n.7, 1986.

STATSOFT. STATISTICA for Windows [Computer program manual]. Tulsa, OK: StatSoft, 2300. Disponível em: <http://www.statsoft.com>. Acesso em: 25/01/2005.

UHL, C.; KAUFFMAN, J. B. Deforestation, fire susceptibility, and potential tree responses to fire in the Eastern Amazon. Ecology, Durhan, v. 71, n. 2, 1990. 